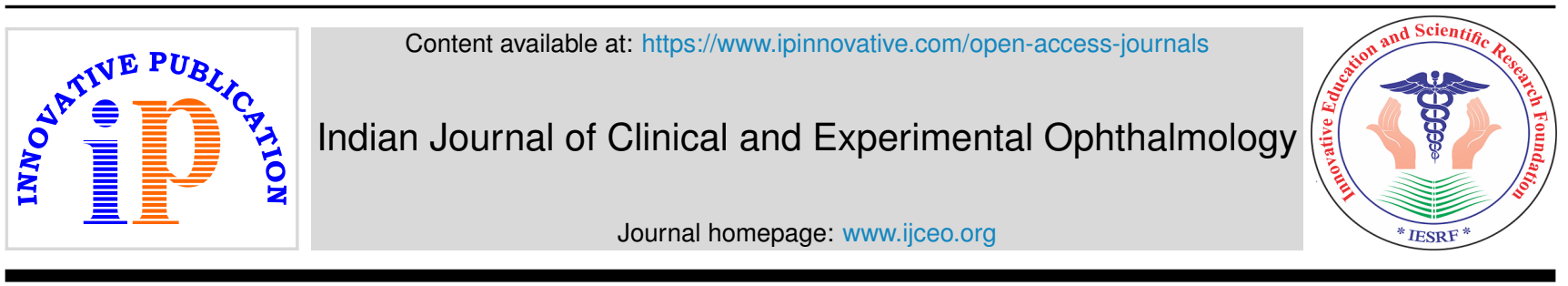

Original Research Article

\title{
Etiological factors \& microbiological characteristics of infectious keratitis in western Maharashtra
}

\author{
Madhuvanthi Mohan ${ }^{1, *}$, Renu Magdum ${ }^{1}$, Sucheta Kaul ${ }^{1}$, Chaitali Desai ${ }^{1}$, \\ Namratha Judith Cardoza ${ }^{1}$, Madhuvanthi Mohan ${ }^{1}$ \\ ${ }^{1}$ Dept. of Ophthalmology, Dr. D. Y. Patil Medical College, Hospital \& Research Centre, Pune, Maharashtra, India
}

\section{A R T I C L E I N F O}

Article history:

Received 03-12-2020

Accepted 15-12-2020

Available online 30-06-2021

Keywords:

Infectious keratitis

Microbiological characteristics

\begin{abstract}
A B S T R A C T
Purpose: To identify the etiological factors and study the microbiological characteristics of infectious keratitis in Western Maharashtra.

Materials and Methods: This was a prospective observational hospital-based study conducted at the Department of Ophthalmology, at a tertiary care hospital, in a part of central India. Data related to socioeconomic status and etiological factors was collected. Results were analyzed on the basis of history, slit lamp examination, microbiological scraping and culture results.

Results: During the period of September 2018 to August 2020, a total of 60 patients with infectious keratitis were examined in the Ophthalmology OPD. Majority of patients of infectious keratitis were between 61 and $70(18.33 \%)$ age group. Incidence in male was higher (68\%) than female. Ocular trauma was the most common etiological factor (52\%). Prevalence of Fungal keratitis (52\%) was higher than bacterial $(46 \%)$ in this part of India. 57\% subjects showed organism on Gram staining. 53\% subjects showed KOH positivity. $68.3 \%$ showed growth over microbiological culture with the most common species isolated as Fusarium species $(26.6 \%)$ followed by Pseudomonas aeruginosa.

Conclusion: Incidence of fungal keratitis is higher in this part of Western Maharashtra. Most common etiological factor was determined to be trauma with vegetative matter among farmers which tells us that they are most prone for infectious keratitis. Prompt diagnosis, microbiological scraping, culture growth identification and starting on appropriate treatment can help reduce the morbidity of corneal ulcers.

(c) This is an open access article distributed under the terms of the Creative Commons Attribution License (https://creativecommons.org/licenses/by/4.0/) which permits unrestricted use, distribution, and reproduction in any medium, provided the original author and source are credited.
\end{abstract}

\section{Introduction}

A predominant cause of blindness in the world today is corneal disease which remains second only to cataract, but its epidemiology is complicated and includes a wide variety of infectious and inflammatory eye diseases. The prevalence of corneal blindness varies from one country to another and even from one population to another, depending on multiple factors, such as availability and general standards of eye care. $^{1}$

Whatever the underlying cause, be it trachoma, corneal ulceration or onchocerciasis, an eye that has become blind from corneal scarring and vascularization usually remains

\footnotetext{
* Corresponding author.

E-mail address: madhuu93@gmail.com (M. Mohan).
}

blind throughout the individual's life. ${ }^{2}$

Agricultural work causing trauma to the cornea, leading to rapidly progressing corneal ulceration and visual morbidity, has largely been overlooked as a worldwide cause of unilateral blindness. ${ }^{3}$

One of the predominant public health problems causing corneal blindness is infectious keratitis. ${ }^{4}$ Microbial keratitis causes around 1.5 million cases every year worldwide of unilateral corneal blindness. ${ }^{3}$

As it affects mainly the poor working class in developing countries, microbial keratitis is frequently neglected and therefore underreported. ${ }^{3}$

1.2 to 2 million cases of corneal blindness globally every year are due to trauma to the eye and corneal ulcers and $90 \%$ of them occur in developing countries. ${ }^{4}$ 
It was estimated that 840,000 people in India develop corneal ulcer in one year. ${ }^{3}$

Corneal epithelium becomes more vulnerable to infections by microbes when certain risk factors are present. Contact Lens Wear (CLW) is frequently associated with severe forms of microbial keratitis. ${ }^{5}$

Etiological factors, urban versus rural location, developed versus developing country, climatic and geographic factors all are known to affect the epidemiology of infectious keratitis. ${ }^{6}$

Viral infections cause the majority of the cases in the population of the Western world compared to the Asian population where fungal and bacterial infections of the cornea are more common. ${ }^{7}$

Corneal trauma, prior ocular surgery, ocular surface diseases, systemic illnesses and misuse or overuse of topical ophthalmic drops result in increased rates of infectious keratitis. $^{8-10}$

According to the WHO, corneal blindness attributed to infectious keratitis is a leading reason for visual disability and it is classified as a 'silent epidemic' taking place all over the world. ${ }^{11}$

Keratitis is considered an ocular emergency requiring immediate and appropriate anti-microbial therapy to prevent permanent vision loss. So, if left untreated, it can have severe consequences. ${ }^{12}$ It can cause significant visual impairment, blindness or even loss of the eye leading to a major impact on an individual's lifestyle. ${ }^{13}$

In developing countries like India, the majority of the expansive population are both socially and economically backward, living in rural areas and pursuing agriculture and other manual labour as their primary source of income. These people are more prone to trauma to the eye due to their occupation. This issue is further worsened by the patient frequently presenting much later to a hospital because of lack of awareness, and inaccessibility to specialized ophthalmic treatment. ${ }^{7}$

Understanding the climate and geography of microbial organisms which are responsible and identifying the predisposing factors helps in diagnosis and directing ophthalmologists to select suitable empirical therapy for its management. Verification by microbiological scraping is required in order to limit the ocular morbidity and thereby, prevent complications. ${ }^{14}$

\section{Materials and Methods}

This was a hospital-based Observational study conducted on patients attending the OPD of Dr. D.Y. Patil Medical College \& Research Institute from September 2018 to August 2020. A total of 60 patients diagnosed with infectious keratitis participated in the study. Ulcers of non-infective etiology, neurotrophic ulcers, ulcers of viral etiology and sterile ulcers were excluded from the study. Approval was taken from Institutional ethics committee before commencing the study. Informed and Written consent was procured from all the patients. The patients were educated about the purpose, course of action, risks and benefits of the study.

A detailed history was taken in all patients. Age, Sex, Demography of the patient was noted. Patient was asked about their presenting complaints, it's onset and duration, diminution of vision, about prior treatment received before they came to our hospital. History of predisposing factors like trauma, type of trauma, velocity of trauma, long term use of topical drugs, history of swimming pool use, exposure to muddy water, history of contact lens wear and the type, duration of contact lens wear and if worn for extended periods of time and during sleep, associated systemic illness like diabetes were all noted down.

Facial appearance was examined to determine any corneal or conjunctival exposure and to look for any lagophthalmos. Visual acuity was recorded with the help of a Snellen's chart.

An external ocular examination was done of the eyelids to rule out any abnormality such as trichiasis, entropion, ectropion, lagophthalmos, proptosis, exophthalmos, blepharitis, meibomitis.

A gross examination of the lacrimal sac area was done to rule out dacryocystitis.

Every patient was then examined thoroughly on the slitlamp. Both palpebral and bulbar conjunctiva was examined for presence of diseases like allergic conjunctivitis.

Pre corneal tear film was inspected and meniscus height was inspected to rule out presence of dry eye and also to see for cells and debris which can be present in an infective corneal ulcer.

Examination of the cornea included the detailed examination of the corneal ulcer. The details of the ulcer were noted down such as the Location of the ulcer, size and shape of the ulcer, it's margins, Stromal infiltration and if there is a presence of a hypopyon, it's size, contour and colour.

Corneal sensations were also assessed with a wisp of cotton to rule out herpetic keratitis.

Once the epithelial defect was stained with the help of fluorescein stain, the size and shape of the ulcer was estimated with the help of a slit-lamp biomicroscope. The size and extent of the infiltration in the stroma and height of the hypopyon was also estimated and noted down.

In case of a bacterial ulcer, a wet surface with distinct borders of the ulcer was noted. Surrounding stroma was usually non-edematous.

In case of fungal ulcer, dry surface and irregular feathery margins of the ulcer was noted. Surrounding epithelial edema, stromal edema, Descemet's membrane folds and stromal infiltration was also documented along with presence or absence of satellite lesions. 
Appropriate documentation of the ulcers was also done in the form of slit lamp photographs and also schematic drawings of the corneal ulcer.

Anterior Chamber examination was carried out to look for anterior chamber inflammation and for hypopyon formation.

Systemic investigations were done to rule out immunocompromised state such as Diabetes mellitus and HIV/HbsAg.

Under sterile conditions, a topical anesthetic drop of $0.5 \%$ proparacaine was instilled in the inferior fornix and scraping of the material was done with the help of a 15number blade. Material was procured by gently and firmly scraping the leading edge and the base of each ulcer and was inoculated onto glass slides for microscopy namely $10 \%$ Potassium Hydroxide mount, Gram and Giemsa stain. Samples were plated onto the following culture media namely Blood Agar, Chocolate Agar, MacConkey Agar and Sabouraud Dextrose Agar. In case of corneal ulcers due to contact lens wear, we scraped the ulcer in most cases while in some cases, we cut up the contact lens into multiple pieces and put them on culture plates. All the bacterial cultures were aerobically incubated at 37-degree C. Cultures on blood and chocolate agar were assessed after 1 day and after 2 days and if they showed no growth, they were discarded.

Once inoculated, the SDA media was incubated at $25^{\circ} \mathrm{C}$ and $37^{\circ} \mathrm{C}$ and inspected every day for three weeks for any growth on the media.

Microbial cultures were accepted to be positive when there was:

1. When 2 or more solid media showed the same organism.

2. The same organism is seen from repeated scrapings.

3. Growth being semiconfluent at the inoculation site on one solid medium and correlating with the pathogen identified of suitable morphology and staining characteristics on Gram or Giemsa stained corneal smears.

\section{Results}

During the period of September 2018 to August 2020, a total of 60 patients examined in the OPD diagnosed as infectious keratitis were included in the study.

Mean age of 60 patients was 45.28 years with the highest 81 years and lowest 8 years. There were $19(32 \%)$ females and $41(68 \%)$ males in the study. $11(18.33 \%)$ samples were from 31-40 \& 61-70 years age group each followed by 10 (16.67\%) subjects in 21-30 \& 51-60 years age group each as seen in Figure 1. (SD 19.36).

Figure 2 shows the prevalence of occupation in the study sample.
The most frequent occupation involved was that of Farmers $(35 \%)$ followed by office workers (18.3\%) and students $(18.3 \%)$.

Left eye was slightly more commonly involved (52\%) than right eye $(48 \%)$ in our patients.

$20 \%$ patients had prior history of treatment before presenting to our OPD.

$31(52 \%)$ patients were having history of ocular trauma while $29(48 \%)$ patients did not. Figure 3 shows us that 10 patients reported history of contact with vegetative matter followed by Foreign body, ${ }^{6}$ stone $^{4}$ and wooden stick $^{3}$ cloth, belt, glass piece, etc. from study samples. Vegetative matter ${ }^{9}$ was most common cause of keratitis among farmers while trauma due to notebook, stone, belt, foreign body, etc. was most common causes of keratitis among students.

Other predisposing factors such as history of contact lens ${ }^{7}$ steroid eye drop ${ }^{1}$ were also present among study samples. Most common causes of keratitis among rural area subjects was due to trauma with vegetative matter while no particular specific cause of keratitis found among urban area subjects.

In Figure 4, 50\% of patients were having lid pathology among study samples. 14 subjects were having blepharitis followed by 9 with blepharitis along with meibomitis among the study sample. Isolated meibomitis was present in 9 subjects, trichiasis ${ }^{2}$ and conjunctival papillae ${ }^{1}$ was also present among study subjects.

Majority of the patients $(75 \%)$ did not have any comorbidities while $22 \%$ were having diabetes mellitus followed by $3 \%$ with rheumatoid arthritis.

Figure 5 shows us that incidence of fungal keratitis $(52 \%)$ was slightly higher than bacterial keratitis $(48 \%) \& 2 \%(1$ patient) with Fungal Keratitis having a bacterial commensal organism.

Table 1 shows us that there is no significant association found between clinical diagnosis and residence (rural or urban) among study sample (Pearson Chi-Square $3.061 \&$ p 0.08).

Table 2 shows us that fungal keratitis was most commonly seen in farmers.

No significant association was found between occupation and diagnosis among study sample (Pearson Chi-Square 5.864 \& p 0.210).

Table 3 shows the association between age groups and diagnosis of ulcer and it was found that bacterial keratitis was most common in 21-30 years age group and fungal keratitis in 31-40 years age group.

Figure 6 shows us the organisms isolated on Gram stain.

In $56.6 \%$ patients (34 patients), the corneal scraping sample showed gram stained structures. 20 (33.3\%) samples were stained gram positive out of which 12 samples showed gram positive cocci and 2 samples with gram positive cocci in pairs. 14 (23.3\%) samples showed gram negative bacilli under microscope. 
In Figure 7, in $32(53.3 \%)$ subjects, there was $\mathrm{KOH}$ positivity. $29(48.3 \%)$ samples showed septate hyphae followed by 2 samples of budding yeast cells (3.3\%) and 1 sample of aseptate hyphae (1.6\%) among study samples.

Table 4 shows us that 23 out of 26 without gram stain sample subjects have $\mathrm{KOH}$ positivity. While 8 subjects are both gram and $\mathrm{KOH}$ positive. No growth seen on $\mathrm{KOH}$ mount in all 10-gram positive cocci and 14 gram negative bacilli.

Figure 8 shows growth over microbial culture where 41 $(68.3 \%)$ subjects show growth over culture while remaining $19(31.6 \%)$ do not show any growth. Fusarium species in $16(26.6 \%)$ patients was the most common organism seen over culture followed by Pseudomonas aeruginosa in $8(13.3 \%)$ patients. Staphylococcus aureus, ${ }^{6}$ aspergillus species, ${ }^{4}$ candida species ${ }^{2}$ etc. were also present in some subjects.

Out of 16, fusarium species were found in 4 subjects who were having diabetes mellitus as co-morbid condition.

3 samples were having pseudomonas aeruginosa growth followed by Streptococcus pneumoniae in 1 subject among 7 contact lenses users.

Fusarium species ${ }^{9} \&$ Pseudomonas aeruginosa ${ }^{6}$ were most common infection among those 36 subjects presented with trauma.

According to Table 5 there was no significant association found between presence of trauma \& infection among study sample (Pearson Chi-Square 0.0513 \& p 0.821).

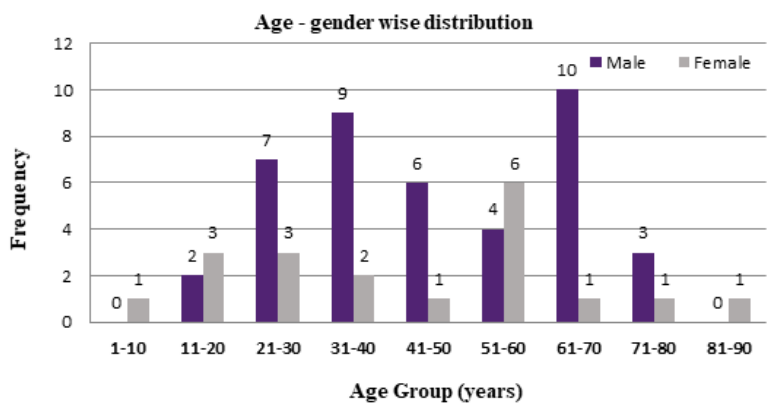

Fig. 1: Distribution according to age and gender in infectious keratitis study sample

Table 1: Association between residential status and diagnosis of the ulcer

\begin{tabular}{lccc}
\hline Diagnosis & $\begin{array}{c}\text { Bacterial } \\
\text { keratitis }\end{array}$ & $\begin{array}{c}\text { Fungal } \\
\text { keratitis }\end{array}$ & Total \\
Rural & 13 & 22 & 35 \\
Urban & 15 & 10 & 25 \\
Total & 28 & 32 & 60 \\
\hline
\end{tabular}

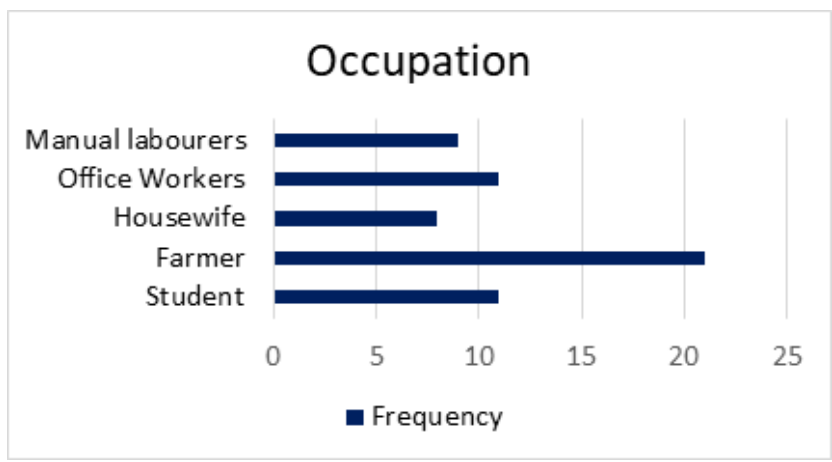

Fig. 2: Prevalence of occupation in study sample

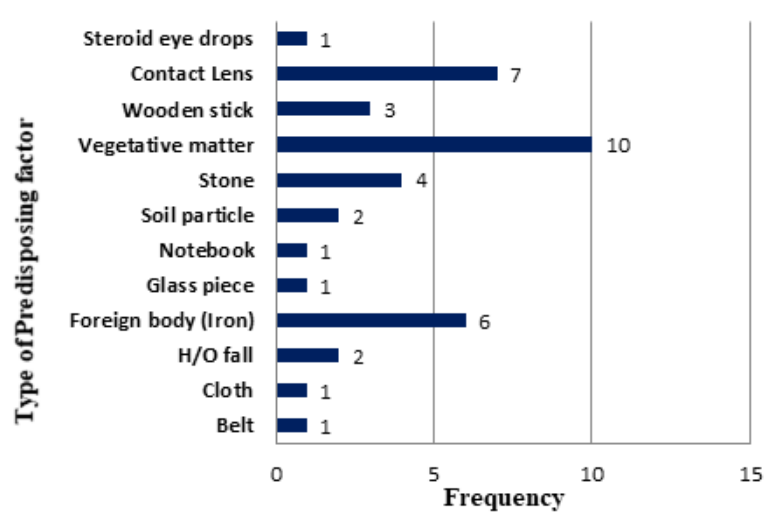

Fig. 3: Prevalence of type of predisposing factor in study sample

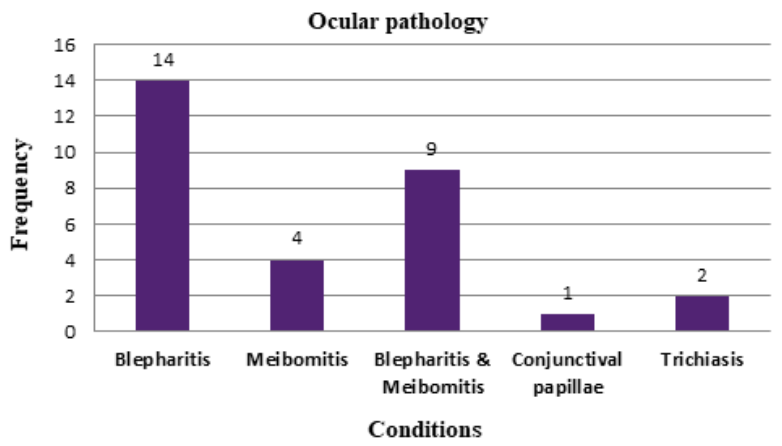

Fig. 4: Prevalence of associated ocular pathologies

Table 2: Comparison between occupation of the study subjects and clinical diagnosis made

\begin{tabular}{lccc}
\hline $\begin{array}{l}\text { Diagnosis } \\
\text { Occupation }\end{array}$ & $\begin{array}{c}\text { Bacterial } \\
\text { keratitis }\end{array}$ & $\begin{array}{c}\text { Fungal } \\
\text { keratitis }\end{array}$ & Total \\
Farmer & 6 & 15 & 21 \\
Housewife & 3 & 5 & 8 \\
Labourer & 5 & 4 & 9 \\
Office worker & 7 & 4 & 11 \\
Students & 7 & 4 & 11 \\
Total & 28 & 32 & 60 \\
\hline
\end{tabular}




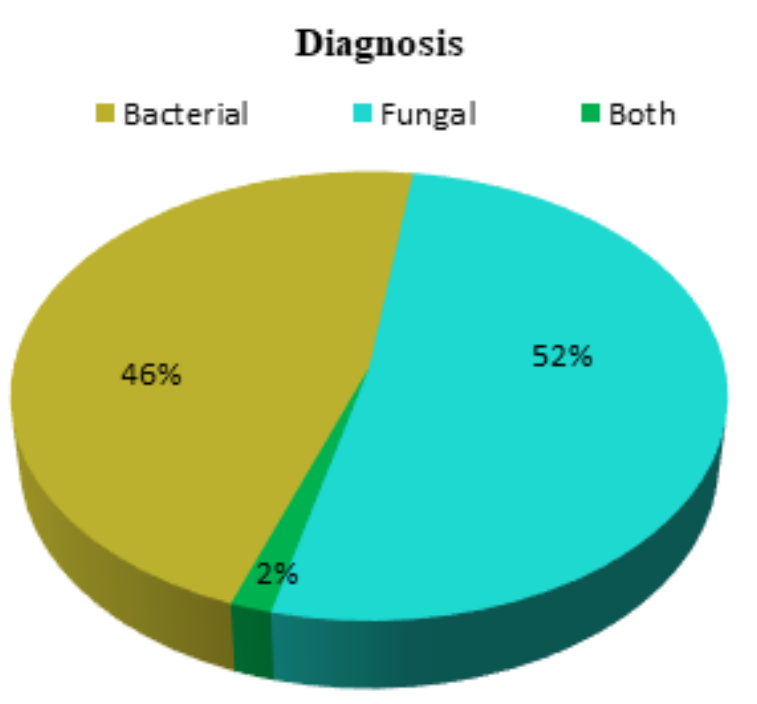

Fig. 5: Diagnosis of corneal ulcers among study samples

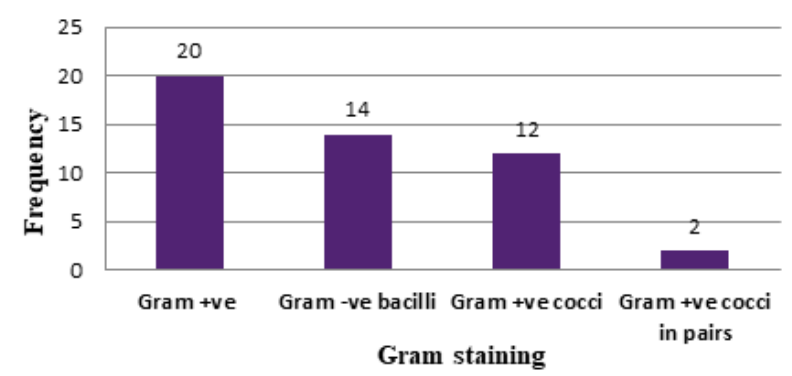

Fig. 6: Isolation of organisms on Gram staining

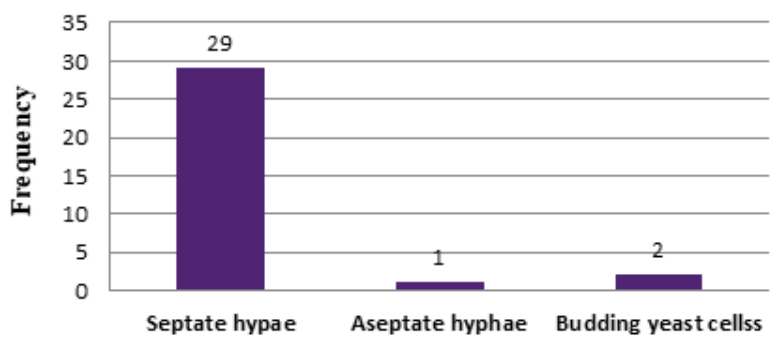

$10 \%$ KOH mount

Fig. 7: Organisms isolated on $10 \% \mathrm{KOH}$ mount

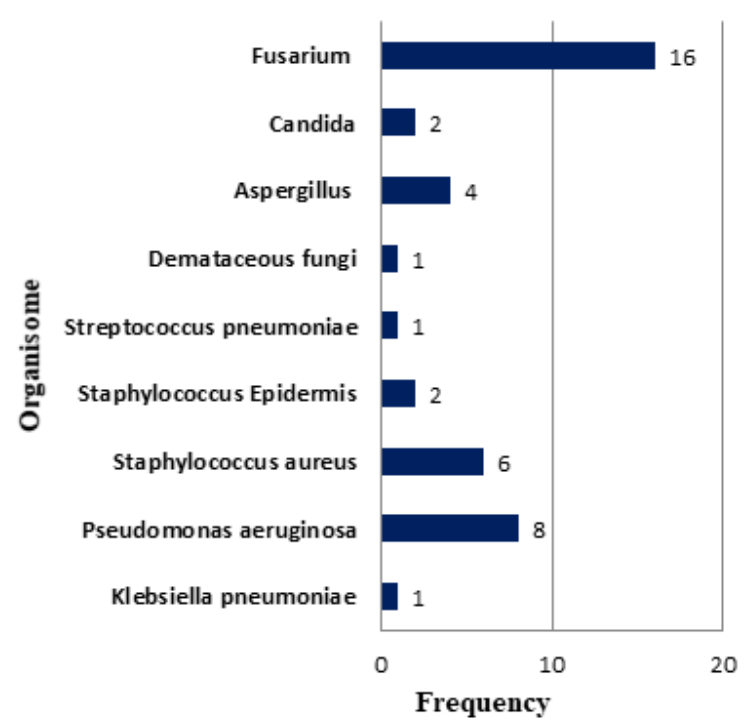

Fig. 8: Growth of organisms over microbiological culture among study subjects

Table 3: Association between age group and diagnosis

\begin{tabular}{lccc}
\hline Age groups & $\begin{array}{c}\text { Bacterial } \\
\text { keratitis }\end{array}$ & $\begin{array}{c}\text { Fungal } \\
\text { keratitis }\end{array}$ & Total \\
$1-10$ & 0 & 1 & 1 \\
$11-20$ & 3 & 2 & 5 \\
$21-30$ & 7 & 3 & 10 \\
$31-40$ & 4 & 7 & 11 \\
$41-50$ & 2 & 5 & 7 \\
$51-60$ & 4 & 6 & 10 \\
$61-70$ & 6 & 5 & 11 \\
$71-80$ & 2 & 2 & 4 \\
$81-90$ & 0 & 1 & 1 \\
Total & 28 & 32 & 60 \\
\hline
\end{tabular}

\section{Discussion}

In our study, mean age of sample size out of 60 patients was 45.28 years with standard deviation of 19.36 years with the youngest patient being 8 years old and oldest patient being 81 years old similar to a study by PN Mohod, ${ }^{15}$ where mean age of patients was 44 years.

In our study, a maximum of 41 males (68\%) and 19 (32\%) females presented with corneal ulcer similar to $\mathrm{S}$ Mehta et $\mathrm{al}^{7}$ and Mohod et al. ${ }^{15}$

There were no significant differences in age and gender in our study sample.

The most common occupation was that of farmers (35\%) followed by office workers and students (18.3\% each), labourers $(15 \%)$ and housewives $(13.34 \%)$ similar to $\mathrm{S}$ Mehta et al. ${ }^{7}$ where a majority $(61.7 \%)$ included farmers, manual labourers and industrial workers while a small percentage of $6 / 7 \%$ were people working indoors. 
Table 4: Correlation between growth on Gram stain and $\mathrm{KOH}$ wet mount

\begin{tabular}{|c|c|c|c|}
\hline Gram stain & & Quantity & Percentage \\
\hline \multirow{2}{*}{$\begin{array}{l}\text { No } \\
\text { detection of } \\
\text { gram stained } \\
\text { organisms }\end{array}$} & $\begin{array}{l}\text { No fungal } \\
\text { elements on } \\
\mathrm{KOH}\end{array}$ & 3 & 5.00 \\
\hline & $\mathrm{KOH}$ positive & 23 & 38.33 \\
\hline \multirow[t]{2}{*}{ Gram + ve } & $\begin{array}{l}\text { No fungal } \\
\text { elements on } \\
\mathrm{KOH}\end{array}$ & 0 & 0.00 \\
\hline & $\mathrm{KOH}$ positive & 8 & 13.33 \\
\hline \multirow[t]{2}{*}{$\begin{array}{l}\text { Gram + ve } \\
\text { cocci }\end{array}$} & $\begin{array}{l}\text { No fungal } \\
\text { elements on } \\
\mathrm{KOH}\end{array}$ & 10 & 16.67 \\
\hline & $\mathrm{KOH}$ positive & 0 & 0.00 \\
\hline \multirow[t]{2}{*}{$\begin{array}{l}\text { Gram + ve } \\
\text { cocci in } \\
\text { pairs }\end{array}$} & $\begin{array}{l}\text { No fungal } \\
\text { elements on } \\
\mathrm{KOH}\end{array}$ & 1 & 1.67 \\
\hline & $\mathrm{KOH}$ positive & 1 & 1.67 \\
\hline \multirow[t]{2}{*}{$\begin{array}{l}\text { Gram - ve } \\
\text { bacilli }\end{array}$} & $\begin{array}{l}\text { No fungal } \\
\text { elements on } \\
\mathrm{KOH}\end{array}$ & 14 & 23.33 \\
\hline & $\mathrm{KOH}$ positive & 0 & 0.00 \\
\hline
\end{tabular}

Table 5: Correlation between history of trauma and presence of infectious keratitis

\begin{tabular}{lccc}
\hline $\begin{array}{l}\text { Infection } \\
\text { Trauma }\end{array}$ & No & Yes & Total \\
No & 8 & 16 & 24 \\
Yes & 11 & 25 & 36 \\
Total & 19 & 41 & 60 \\
\hline
\end{tabular}

Out of 21 farmers who presented with infectious keratitis, 15 were diagnosed with fungal keratitis while 6 were diagnosed with bacterial keratitis. But there was no association found between occupation and diagnosis among our study sample. This showed that the patients involved in outdoor activities mainly farming were more predisposed to trauma to the eye. This is in accordance to a study by PN Mohod, ${ }^{15}$ majority of the patients presenting with corneal ulcers were farmers $(42.04 \%)$.

In our study, $36(60 \%)$ subjects presented with a history of ocular trauma, out of which a maximum of 10 subjects had a history of trauma with vegetative matter.

Vegetative matter ( 9 subjects) was the most common cause of keratitis among farmers while trauma due to other material was more common among students.

Patients in rural area $(58.3 \%$ ) were more affected by trauma with vegetative matter while there was no particular cause of keratitis in urban population. (41.6\%).

We found no correlation between presence of trauma and infectious keratitis among the study sample $(\mathrm{p}=0.821)$.

Malhotra, et al. ${ }^{16}$ showed similar findings with trauma to the eye as the most common etiological factor (73.3\%). 84 patients $(46.7 \%)$ were agricultural workers among whom 66 (78.6\%) of these patients had trauma with a sugarcane leaf before developing corneal ulcer.

According to Bharathi et al. ${ }^{17}$ in a study based on fungal keratitis, the percentage of subjects with corneal trauma was significantly higher than subjects with trauma due to other agents $(\mathrm{p}<0.0001)$.

In our study, after trauma, the most common ocular predisposing factor was history of use of contact lens in 7 subjects all of which were usage of monthly disposable soft contact lenses followed by one patient with usage of steroid eye drops similar to U Gopinathan, et al. ${ }^{12}$

30 out of 60 patients $(50 \%)$ presented with associated ocular pathology with 14 (23.33\%) subjects showing blepharitis, $9(15 \%)$ subjects showing meibomitis and 9 $(15 \%)$ subjects showing both blepharitis and meibomitis. 2 patients also presented with trichiasis and 1 with conjunctival papillae.

According to a study by Jampala, et al. ${ }^{11}$ in 49 patients, among ocular disorders, lid disorders were the primary causes with blepharitis $7 \%$ among the study subjects.

S Mehta, et al. ${ }^{7}$ showed a total of 7 (11.67\%) patients with abnormalities of the lid margin namely severe blepharitis/meibomitis, trichiasis and entropion out of 60 patients.

In our study, a clinical diagnosis was made of 31 (52\%) subjects having fungal keratitis and $28(46 \%)$ subjects with bacterial keratitis. $1(2 \%)$ subject showed a fungal keratitis with a bacterial commensal.

Tewari, et al. ${ }^{18}$ reported fungal and bacterial aetiology seen in 89 out of 150 patients presenting with corneal ulcers.

According to Bharathi et al, ${ }^{17}$ a clinical diagnosis of fungal keratitis made by ophthalmologist was $94.1 \%$

In our study, all the 60 subjects were scraped and subjected to both gram staining and $10 \% \mathrm{KOH}$ mount. A total of $34(56.67 \%)$ subjects showed gram stained structures, out of which $33.3 \%$ were gram positive $23.3 \%$ subjects showed gram negative bacilli.

On doing 10\% $\mathrm{KOH}$ mount for our sample size of 60 subjects, a majority of the subjects (53\%) showed $\mathrm{KOH}$ positivity while $47 \%$ were negative for $\mathrm{KOH}$. In these smears which were positive for KOH, 29 (48.3\%) samples showed presence of septate hyphae, 2 (3.33\%) samples showed budding yeast cells and $1(1.67 \%)$ sample showed aseptate hyphae.

$8(13.33 \%)$ patients showed both Gram positivity as well as $\mathrm{KOH}$ positivity.

$3(5 \%)$ smears out of 60 smears were negative which correlated with no culture growth.

Correlation between detection of organisms on Gram stain and $\mathrm{KOH}$ smear in our study was statistically insignificant.

In a study by AK Leck et al, ${ }^{19} 31 \%$ cases had no definitive lab diagnosis. Gram positive cocci were seen in $80 \%$ of smears. 
According to Bharathi et al, ${ }^{17}$ the sensitivity of $\mathrm{KOH}$ wet mount preparation was higher $(99.23 \%)$ than Gram stain $(88.73 \%)$ in detecting fungal filaments.

According to Sharma $\mathrm{S}$ et al, ${ }^{20} \mathrm{KOH}$ method is as sensitive as other conventional methods in the diagnosis of mycotic keratitis. They recommend that all smear-positive cases of mycotic keratitis be treated accordingly despite negative culture reports.

In our study, majority of subjects, $41(68.33 \%)$ showed growth over culture while $19(31.6 \%)$ did not show any growth. The most common organism isolated in culture was Fusarium species (26.6\%) followed by Pseudomonas aeruginosa $(13.3 \%)$.

Staphylococcus aureus (10\%), Aspergillus species (6.6\%) and Candida species (3.3\%) were also present among the subjects.

While in our study, the most common bacterial pathogen seen was Pseudomonas aeruginosa (13.3\%), in Malhotra et al ${ }^{16}$ and S Mehta et al. ${ }^{7}$ showing Staphylococcus aureus as the most common bacterial pathogen.

A multicentre study was executed in Ghana and southern India by $\mathrm{A} \mathrm{K}$ Leck et $\mathrm{al}^{19}$ to find out the aetiology of infectious keratitis in two regions with similar tropical latitudes. Major cause of infection were fungal organisms (also included mixed infections): $44 \%$ in South India and $37.6 \%$ in Ghana. Bacteria was isolated from $29.3 \%$ of cases in south India and $13.8 \%$ in Ghana. The most routinely isolated organisms in Ghana were Pseudomonas species whereas in India the commonest bacterial organisms were streptococci.

Keshav BR et $\mathrm{al}^{21}$ in a retrospective analytical study of 188 patients concluded that $43.18 \%$ of cases showed positive culture of which $88.2 \%$ were bacteria and remaining were fungal isolates. Of the bacteria $53.84 \%$ were pseudomonas, and $20 \%$ staphylococcus.

In our study, 41 (68.3\%) subjects showed growth over culture while $19(31.6 \%)$ did not show any growth. This is similar to Mehta et al, ${ }^{7}$ where 43 subjects were culture positive and the remaining 17 patients failed to give a positive culture. This could have been due to less availability of material for scraping.

Fungal pathogens isolated were common than bacterial pathogens in our study similar to Mohod et al. ${ }^{15}$ Fusarium was the most commonly isolated species in our study which was similar to Srinivasan et $\mathrm{al}^{22}$ and Mohod et al. ${ }^{15}$ while in S Mehta et al, ${ }^{7}$ Aspergillus species was more commonly isolated. This could be due to change in climate as well as the environmental differences in the different regions where the studies have taken place.

\section{Conclusion}

In our study, in a tertiary care hospital in Western Maharashtra, there was almost equal diagnosis of Fungal and bacterial keratitis with Fungal keratitis being slightly more prevalent and with trauma as the commonest etiological factor. Infectious suppurative keratitis is a sight-threatening disorder of utmost emergency which can be limited with patient education regarding personal hygiene, early presentation to OPD following trauma, proper scraping and material collection on smears, wet mount as well as microbiological culture examination.

A good compliance with the antibiotic or antifungal medication prescribed by Ophthalmologists is required and regular follow up to prevent further complications.

Early clinical diagnosis, proper corneal scraping and appropriate medical therapy can go a long way to reduce the ocular damage of this disease.

\section{Source of Funding}

None.

\section{Conflict of Interest}

The authors declare that there is no conflict of interest.

\section{References}

1. Smith GTH, Taylor HR. Epidemiology of Corneal Blindness in Developing Countries. $\quad J$ Refract Surg. 1991;7:436-9. ब0i-103928/108ा-597x-1090101-07.

2. Whitcher JP, Srinivasan M, Upadhyay MP. Corneal blindness: a global perspective. Bull World Health Organ. 2001;79(3):214-21.

3. Whitcher JP, Srinivasan M, Upadhyay MP. Prevention of Corneal Ulceration in the Developing World. Int Ophthalmol Clin. 2002;42(1):71-7. 101:10.1097100004397-200201000-00010.

4. Kumar A, Pandya S, Kavathia G, Antala S, Madan M, Javdekar T. Microbial keratitis in Gujarat, Western India: findings from 200 cases. Pan Afr Med J. 2011;10:48.

5. Sousa SJF, Dias VG, Marcomini LAG. Bilateral Acanthamoeba ulcer in a user of disposable soft contact lenses: a tragic incident or a consequence of the aggressive policy of soft contact lens trading? Arq Bras Oftalmol. 2008;71(3):430-3. 10i:10.1590/s000427492008000300025.

6. Ibrahim YW, Boase DL, Cree IA. Factors Affecting the Epidemiology ofAcanthamoebaKeratitis. Ophthal Epidemiol. 2007;14(2):53-60. 101:10.1080/09286580600920281

7. Mehta S, Mehta M. Clinical and Microbiological Profile and Treatment Outcome of Infective Corneal Ulcers: A Study in Central India. Int J Sci Stud. 2017;4(12):234-8.

8. Lam DS. Incidence and risk factors for microbial keratitis in Hong Kong: comparison with Europe and North America. Eye (Lond). 2002;16(5):608-18.

9. Schaefer F. Bacterial keratitis: a prospective clinical and microbiological study. $\quad B r \quad J$ Ophthalmol. 2001;85(7):842-7. dol:10.1136/bj0.85.7.842.

10. Bourcier T. Bacterial keratitis: predisposing factors, clinical and microbiological review of 300 cases. $\mathrm{Br} J$ Ophthalmol. 2003;87(7):834-8. doi:10.1136/bjo.87.7.834.

11. Srinivas J. Epidemiological and Microbiological Profile of Infective Keratitis in a Tertiary Care Centre, South India. Asian J Biomed Pharm Sci. 2014;4(37):44-51. do1:10.15272/ajbps.v4137.616.

12. Sharma S, Garg P, Rao GN, Gopinathan U. Review of epidemiological features, microbiological diagnosis and treatment outcome of microbial keratitis: Experience of over a decade. Indian $J$ Ophthalmol. 2009;57(4):273-9. 10:-10.4103/0301-4738.5305]

13. Chidambaram JD. Epidemiology, risk factors, and clinical outcomes in severe microbial keratitis in South India. Ophthalmic Epidemiol. 2018;25(4):297-305. 
14. Paty BP, Maitreyi T, Padhi S, Parida B. Clinico-Microbiological Profile of Infective Keratitis in a Tertiary Care Hospital, Eastern India. Int J Clin Biomed Res. 2019;4(54):14-7. doi:10.31878/1icbr.2019.54.04

15. Mohod PN, Nikose AS, Laddha PM, Bharti S. Incidence of various causes of infectious keratitis in the part of rural central India and its visual morbidity: Prospective hospital-based observational study. $J$ Clin Ophthalmol Res. 2019;7(1):31-4. [01:10.4103//1cor.jcor_16 18

16. Malhotra C, Nagpal RC, Soni R, Bahadur H. Demographic and aetiological profile of microbial corneal ulcer in a hill state in North india. Asian J Ophthalmol. 2011;12:211-5.

17. Bharathi MJ, Ramakrishnan R, Vasu S, Meenakshi R, Palaniappan R. Epidemiological characteristics and laboratory diagnosis of fungal keratitis. A three-year study. Indian J Ophthalmol. 2003;51(4):31521.

18. Sood N, Tewari A, Vegad MM, Mehta DC. Epidemiological and microbiological profile of infective keratitis in Ahmedabad. Indian J Ophthalmol. 2012;60(4):267-72. 10:-10.4103/0301-473898702

19. Leck AK. Aetiology of suppurative corneal ulcers in Ghana and south India, and epidemiology of fungal keratitis. $\mathrm{Br} J$ Ophthalmol. 2002;86(11):1211-5

20. Sharma S, Silverberg M, Mehta P, Gopinathan U, Agrawal V, Naduvilath TJ. Early diagnosis of mycotic keratitis : Predictive value of potassium hydroxide preparation. Indian J Ophthalmol. 1998;46:31-5.

21. Keshav BR, Zacheria G, Ideculla T, Bhat V, Joseph M Epidemiological characteristics of corneal ulcers in South sharqiya region. Oman Med J. 2008;23(1):34-43.

22. Srinivasan M, Gonzales CA, George C, Cevallos V, Mascarenhas $\mathrm{JM}$, Asokan B, et al. Epidemiology and aetiological diagnosis of corneal ulceration in Madurai, south India. $\mathrm{Br} J$ Ophthalmol. 1997;81(11):965-71. doi:10.1136/bjo.81.11.965.

\section{Author biography}

Madhuvanthi Mohan, Junior Resident

Renu Magdum, Professor and HOD

Sucheta Kaul, Junior Resident

Chaitali Desai, Junior Resident

Namratha Judith Cardoza, Junior Resident

Cite this article: Mohan M, Magdum R, Kaul S, Desai C, Cardoza NJ, Mohan M. Etiological factors \& microbiological characteristics of infectious keratitis in western Maharashtra. Indian J Clin Exp Ophthalmol 2021;7(2):402-409. 